as a patient, of which he had more than his fair share, moulded his attitude to patients, colleagues and to life in general.

As a medical student in the USA he developed tuberculosis, from which he suffered for four years, much of which he spent flat on his back. He often spoke of how deeply impressed he was by the observation that whether his fellow patients got better or worse depended to a significant degree on their emotions - a finding that he not only applied to himself, but that moved him towards a career in psychoanalysis

He was unfortunate to be given a 'second dose' of such learning when he developed poliomyelitis during his training as registrar at the Maudsley and spent 18 months off work, several weeks of which he spent in an iron lung. He later spoke of his state of mind of helpless dependency at this time, and of the importance of his relationships with staff looking after him, including the ward cleaner who seemed to be very energetic with her broom around the life-saving electric plug on which he was dependent!

These experiences, and his analysis with Wilfred Bion, also gave him a lifelong interest in group and institutional processes. He was very influential in the design of many training courses, both at the Tavistock and elsewhere, ensuring that they harnessed the innate group dynamics available for learning.

With colleagues such as Eric Miller, Gordon Lawrence, Pierre Turquet and others, he was strongly involved in the Leicester Group Relations Conferences that brought together professionals from fields as far apart as health, industry and government in order to study matters of leadership and authority in organisations, and significantly stretched the boundaries of understanding with his classic paper on very small groups. He was also centrally involved with the work of the Royal College of Psychiatrists, and organised the enormously successful 1964 International Conference on Psychotherapy.

In late middle age his hearing failed, and he decided to take early retirement from the NHS. In recognition of his work he was awarded the OBE.

He and his wife, the novelist Veronica Henriques, retired to Gloucestershire. Together they restored a Queen Anne house, and he took up his hobbies of carpentry and part-time farming. He never lost his capacity to support friends and colleagues alike, and did so till his last few hours.

He is survived by his wife, four sons and a daughter.

Anton Obholzer

\section{Ben Porges}

Endowed the Foundation Chair in Old Age Psychiatry,

University of Manchester

Ben Porges died on 6 December 1999. He was an engineer by training who founded a company, Flexibox, which became widely known and widely respected in the engineering field, in particular in relation to oil pipelines. His contribution to psychiatry will not at first be obvious to readers of this journal, but he endowed the Foundation Chair in Old Age Psychiatry in the University of Manchester. His wife, Marianne, died of Alzheimer's disease and it was to honour her memory that he funded the Chair. He kept an active interest in the field and used his connections to further research funding.

When university and health service money is tight, endowments like this are a welcome and a necessary vehicle to fund academic developments. It is poignant that a contribution like this should grow out of such personal tragedy but this makes the contribution even more significant in personal terms.

Alistair Burns and David Jolley 